\title{
From Sustainable Publishing To Resilient Communications
}

\author{
David Ottina
}

\author{
Open Humanities Press, London, UK, davido@openhumanitiespress.org, \\ http://openhumanitiespress.org
}

\begin{abstract}
In their opening reflection on Open Access (OA) in this special section, Fuchs and Sandoval (2013) argue the current policy debate on Open Access publishing is limited by a for-profit bias which blinds it to much of the most innovative activity in Open Access. They further argue for a refocusing of the policy debate within a public service, commons based perspective of academic knowledge production. I pick up these themes by looking at another key term, sustainable publishing, in an effort to contextualize the policy debate on OA within the broader context of the privatization of the university. From this perspective, the policy debate reveals an essential tension between top-down and bottomup cultures in legitimizing knowledge. This is a tension that has profound implications for scholarly practices mediated through digital networked communications. Explicitly acknowledging this fundamental tension gives additional insight into formulating strategies for maintaining an academic culture of free and open inquiry. I suggest that the frame of resilient communications expresses the dynamic nature of scholarly communications better than that of sustainable publishing, and that empowering scholars through practice-based OA initiatives is essential in broadening grass roots support for equitable Open Access amongst scholars.
\end{abstract}

Keywords: open access, scholarly communications, academic publishing, universities, knowledge

\section{Context}

At Creative Commons' annual summit in 2007, its founder, Lawrence Lessig, announced he was moving on from being a copyright activist to focus his activism on the corrupting influence of money in politics: "From a public policy perspective, the question of extending existing copyright terms is, as Milton Friedman put it, a "no brainer." As the Gowers Commission concluded in Britain, a government should never extend an existing copyright term. [...] Yet governments continue to push ahead with this idiot idea [...] Why?"(Lessig 2007).

What is unsettling to Lessig here, I think, is not just the spectre of perpetual copyright on the instalment plan. Rather that in the rationale of copyright law (private economic incentive for ultimate public benefit), copyright extensions are bad policy, yet they always win. The success of copyright extension is a failure of our political institutions to act in the public interest even within the narrow economic terms of contemporary political discourse. It unmasks the politics of policy, showing them to be frequently about maintaining advantage for entrenched interests. This is nothing new. The tension between public good and private interests is an enduring feature of our political institutions and the history of copyright term extensions is an informative case study. In recent years, however, the public interest has been largely redefined as corporate interest. Concomitantly, the culture of corporations, managerialism, has become synonymous with optimal organization. The idea that public institutions have fundamentally different aims, calling for significantly different cultures and governance structures, has all but vanished from official policy discussions. It is no longer possible to critique the tenets of managerialism and be taken seriously within the policy debate.

Increasing managerialism is not of course restricted to political rhetoric but is part of a much broader trend towards the wholesale replacement of public institutions with private ones. The university is feeling this move in all of its aspects, not just scholarly communications. In the English-speaking countries, we see an increasingly managerialist culture in our university administrations. To name but a few impacts: the channelling of resources towards immediately monetizable research, over-reliance on metrics of questionable validity, and the 
separation of managerial (administrative) careers from academic ones. Public institutions, although they remain publicly funded and legally not-for-profit, are administered with, and evaluated by, the same values and practices as for-profit corporations under the premise that corporate cultures always produce more effective outcomes. This is the institutional context within which the Open Access (OA) movement finds itself.

In their reflection on OA, Fuchs and Sandoval (2013) argue for a refocusing of the policy debate on a public service, commons-based perspective of academic knowledge production. I agree, but instead of discussing the rhetoric created by the Open Access movement itself as Fuchs and Sandoval do, l'd like to analyse the rhetoric that the OA movement has had imposed upon it by other actors. In particular, my concern is with the notion of "sustainable publishing" and with its interplay within the broader institutional and technical contexts.

\section{What Needs Sustaining?}

Cahiers pour l'analyse, widely regarded in continental philosophy and critical theory circles as one of the most influential journals of the 20th century, was active for a mere three years. Surfaces, an early influential Open Access journal, was published electronically and bilingually for ten years from 1991 to 2001 . All of its articles are still openly accessible online. Sustainable publishing invokes a picture of scholarly publishing as a mature, stable, largely static practice but this view obscures the fluid and dynamic nature of scholarly communications themselves. These dynamics involve the establishment of new fields of inquiry and, with them, new venues and modes of communication, not all of which necessarily have longevity. The idea of sustainable publishing occludes the fact that the practices of scholarship have been intertwined with the technologies of communication in complex social formations from their inception. Surely, with all the current emphasis on innovation and growth, we aren't after a stagnant communications system. So what are we talking about when we talk about sustainable publishing?

Most frequently, and especially within the policy-level discussion, the mention of sustainable publishing is quickly followed by an appeal to the notion of the business model. Business model is usually used in the OA debate as a synonym for a revenue or funding model. It is the answer that people give to the question: "where does the money come from?". This is, of course, a critical aspect of business, but it is not the only one requiring consideration. More typically, business models include the full set of strategies employed to capture and maximize revenues. In this sense, the business model is the way a business takes and defends market share, how it erects and maintains barriers to entry for competitors, and how it constructs barriers to exit for customers - all in order to maximize profit. Hence when the OA discussion shifts to sustainable business models, it invariably becomes a discussion about the publishing business. The implication is that what needs sustaining are the publishers themselves.

Many, if not most, learned societies began as informal affiliations, created to facilitate communication among scholars and promote disciplinary identities. Not long after the earliest scholarly societies were formalized under royal charters, they began publishing their proceedings. At the time, printing presses were tightly regulated, and the editorial function was part of the role of publisher/censor. Royal society editors, however, operated fairly autonomously as trusted supporters of the Crown (Biagioli 2002, 15). Society proceedings augmented the informal system of written correspondence, helping scholarship to grow and diversify. As the roles of publisher and censor diverged in the 18th century, editorial review was distributed across members to accommodate increasing specializations. As Ray Spier (2002) outlines, innovations in printing in the 19th century led to an over-supply of journal pages. In response, editorial teams grew and became more active in eliciting and developing content, including for the first time reviews and commentary to fill out issues and expanding their curatorial remit in the process. The ability to make a few copies easily and cheaply, firstly with carbon paper and later with photocopiers, allowed multiple peer reviewers per article (Spier 2002, 358). Although a few university presses were contemporaneous with the first learned societies, most were founded in the 20th century as campus print shops. While at 
first the university presses focussed on publishing scholars from their home institutions, they soon expanded beyond their home institution's boundaries, reflecting the international character scholarly activity.

By the mid-20th century, then, scholarly publishing was characterized by a diverse set of small institutionally-embedded publishers anchored in the materialities of print. This was reflected in prices that were set to cover costs and competition focused on prestige rather than margins. After all, publishing was simply a service to scholars and their institutions, not a core activity of scholarship. The free labour that scholars provided in the form of peer review and editing was regarded as service to the profession; everyone did some extra work, and everyone benefited by having a corpus that met quality standards set collectively. Scholarly publishing had developed alongside print technology as an increasingly codified set of practices to authorize knowledge and facilitate its distribution. The access question was limited to the logistics of paper copies. To be sure, this system was not without its problems, but the public and civil sector provision of research dissemination services harmonized reasonably well with the public goods character of knowledge, in part, because it was largely driven by scholars themselves.

Commercial academic publishers became major players in scholarly communications relatively late. Elsevier launched its first international science journal in 1947, for example (Elsevier 2005, 4). But it didn't take long for commercial publishers to realize they were sitting on an outstanding business opportunity. The fundamental opportunity, as many have pointed out, is the non-substitutable nature of research articles coupled with mostly externalized costs. In principle, every article is its own monopoly and every publisher its own cartel. Publishers frequently argue that the value they add justifies their prices. But the prices and resulting margins are primarily determined by their hold on the cycle of scholarly communications, not the value-add.

In order to penetrate the academic market, commercial publishers began approaching prestigious publications and offering to take care of the business side of things for them. This was attractive to editors as it freed them to focus on content development and certification, leaving the tedious logistic details to the commercial players. It was attractive to commercial publishers, too, because the labour split left the difficult-to-automate work fully externalized with scholars and their institutions, while enabling them to capture the most valuable titles. At this juncture, no one really knew how high journal prices could go. The only way to find out was to continue raising prices until libraries started cancelling subscriptions. Titles in hand, this is exactly what the big publishers did (Edwards and Shulengurger 2003). In an economy of prestige, price hikes can have several strategic benefits to price raisers. In addition to commanding higher margins, prestigious titles have the greatest barriers to exit for customers. Raising prices led to cuts, but it was other titles that were cut. Squeezed library budgets blocked new entrants while locking in cumulative advantage for the retained titles. When prices got high enough, libraries were forced to shift budgets by cutting other segments and services (Young 2009, 4). Perhaps unsurprisingly, monographs were the first and hardest hit, endangering university presses in the process. Hours, headcounts and, crucially, core operations have all suffered as well. Many of the larger learned societies with title portfolios of their own remained independent, but soon adopted the same strategies with similar effects.

By the 1980s, the largest commercial and society publishers had developed significant portfolios of high prestige titles. Information technology had matured to a point where it was becoming essential to researchers through catalogues, citation indexes, and databases. Purchasing agents like EBSCO morphed into content aggregators and providers of electronic resources. They offered access to electronic resources with low additional cost if libraries would promise not to cancel print journal subscriptions, effectively underwriting their digital retooling through the public purse rather than capital markets. Predictably, with these additional barriers in place, serials costs continued to rise, taking ever greater shares of library budgets as they did, and resulting in more market share for incumbent publishers, and the growing subsumption of library functions by publishers and aggregators.

By the end of the 1990s, the squeeze on library budgets had become so extreme that libraries were banding together in purchasing consortia in order to counter the tremendous 
market power that the consolidated incumbent publishers now held. Incumbent publishers responded with ever larger bundles of content and services: the infamous "Big Deal". Despite (or perhaps because of) Big Deals, materials costs to libraries have continued to rise, and incumbent publishers' market power has magnified by effectively placing a stranglehold on library purchasing channels. By 2007, the original 40 major academic publishers had reduced to a mere 6 (UC Berkeley Library 2012). According to the Association for Research Libraries (2011), whose members include many of the largest university libraries in North America, between 1986 and 2011 serials prices rose 402\% while library headcounts per student fell by $38 \%$. By 2012, Elsevier, Wiley and Springer's bundle penetration rates were 92$96 \%$ of all ARL libraries (Strieb and Blixrud 2013,14). Incumbent publishers have been good at raising margins but even better at neutralizing rivals, increasing market share, capturing purchasing channels, and locking in customers.

What often goes unremarked in this relatively well-known narrative is how cuts to library and university press budgets are symptoms of the same thinking that holds up incumbent publishers as paragons of sustainability, even though scholarly communications have been in financial crisis since their arrival. This would be the belief that market discipline is always the best mechanism to enforce efficient, accountable operations. Even though university budgets have risen much faster than inflation in recent years (Odlyzko 2013, 14), university presses have been forced to become self-sustaining and are increasingly required to become net revenue generators. Many have not made the transition. Those that have survived have done so by shifting their publications to more profitable segments and focusing on marketability if not over, at least alongside, scholarship. Whether intentional or not, this places profitability over academic consensus as the primary arbiter of legitimacy. One of the most obvious side effects of market-as-arbiter is of course to disadvantage smaller communities, including emerging fields of inquiry and non-colonial languages. The scholarly communications supply chain has transformed from one characterized by many small presses into one dominated by large publishing cartels, aggregators and purchasing consortia. Universities and libraries have accepted ephemeral gains in provisioning at the cost of permanent loss of capacity and capability. Disciplinarily distinctive practices have been papered over to meet the requirement of large-scale centralized operations. We seem to have forgotten that scholarship and indeed the early Internet developed into rich and expansive terrains of knowledge-creation and sharing precisely because they scaled horizontally in bottom-up fashion, not vertically through top-down controls.

Open Access arose in part as a reaction to the opportunities emerging from the shift from print to digital, and in part as a response to the serials crisis outlined above. Large commercial publishers in particular have engendered a lot of hostility over margins that are seen as excessive. Some scholars feel taken advantage of when labour provided in the spirit of collegiality is appropriated for private gain. Incumbents, in turn, have reacted with hostility, arguing that OA destroys quality, interferes with academic freedom, and will bankrupt them. This has bought incumbents some time as they chart a course that will allow them to retain the market power they need to sustain the margins their investors expect. Sensing that they were alienating the scholarly community, incumbent publishers have since become more publicly supportive of $O A$, as long as it is sustainable.

As my recounting of the serials crisis has emphasized, the OA discussion of business models (cast as sustainable publishing) needs to pay closer attention to the strategies of incumbents, not just to the question of revenue sources. In particular, to how business strategies interact with networked information technologies to impact the practice of scholarship. As PLoS has demonstrated, revenue derived from Article Processing Charges (APCs) is enough not only to survive, but also to thrive (PLoS 2012). Community models similarly demonstrate that the hard costs and capital requirements of publishing are low enough to be inconsequential (Willinsky and Mendis 2007). Both of these approaches effectively neutralize the Big Deal barrier to entry because direct access to library revenues isn't critical to operation. By understanding that the ultimate sources of prestige are scholars themselves, PLoS has also eliminated the primary barrier to exit for scholars in its fields. Community publishers still struggle with the prestige barrier but there are reasons to be optimistic here as well. The 
true threat of $O A$ to incumbent publishers is the elimination of barriers that give incumbents the market power to sustain outsized margins. It is a problem of profitability, not survivability, as is so often insisted. From the point of view of incumbents, what needs sustaining are large margins. Today, the business strategies that are being developed to maintain effective barriers are shifting from publications to the practice of research itself. This has profound implications for the way knowledge is authorized.

Talking about publishing rather than about communications puts publishers rather than scholars at the centre of the debate. From the scholarly perspective, what needs sustaining is not publishers, but rather a communication system that supports its culture of inquiry. That is to say, what needs to be sustained ultimately is the culture of free critical inquiry certified by the rigors of open collaboration. Academic culture as free critical inquiry is undergoing delegitimization under the veil of public oversight and disintermediation in the name of economic efficiency. Talk of sustainable publishing implicitly values static over dynamic, large over small, private over public, monoculture over diversity, and top-down over bottom-up. Note that by this I'm not suggesting that financial concerns are entirely beside the point or that publishers and publications are irrelevant. It is simply that "sustainable publishing" invokes the wrong frame for understanding the stakes and dynamics of scholarly communications.

\section{Resilient Communications}

We are accustomed to thinking of our universities as immutable edifices of stability. But managerialism often brings with it steeper hierarchies of power. Priorities are susceptible to rapid changes driven from above. What is true of universities is even more pronounced in public agencies. Education policy has become a political plaything in the drive to privatization, and ground rules shift with each new government. The global financial crisis has shown us that when large business fail they fail catastrophically. In short, volatility is a better characterization of our current institutional context than stability. The frame of resilient communications fits these dynamics better than does the simple commodification of "sustainable publishing". Resilient systems absorb disturbance, transforming when necessary to retain their essential function and identity. Resilience depends on the diversity that gives it a ready pool of responses to volatile conditions.

The Open Access movement has already spawned many independent projects which, taken together, are developing a robust and resilient system of scholarly communications. Such projects are experimenting with the aspects of scholarly communications that interest them, whether they are traditional publications, changes in practice like open peer review and authorship, tool development for production and distribution, or something entirely new altogether. There is very little in the way of direct coordination or even direct communication between these groups except for a shared awareness of the OA landscape and a shared commitment to scholarly values. Nevertheless, taken as a whole, these projects effect a kind of coordination. The strength of this type of organizational structure is its resilience, fluidity and speed in the face of changing conditions and, ultimately, its capacity for transformative innovation. The diversity of these projects creates opportunities for people to participate in various capacities and at various levels of commitment. This diffuse structure is not destined to converge on a single solution. It does however produce basins of attraction, projects that gather significant numbers of participants and mature into defining examples. Eventually some of these projects attract cross-institutional support on collective terms. However small projects, with more specialized remits, remain an important part of the intellectual ferment and are critical to maintaining diversity.

Well-funded disciplines can solve their own access problems through large, well-funded efforts. These in turn produce technical solutions that are widely adopted. For example, The National Library of Medicine's journal publishing tag set (NLM-DTD), developed for PubMed, is becoming the de facto standard for document semantics. Still other projects, such as PKP's open source journal publishing software, OJS, integrate these standards into their systems making them accessible to OA journals. This in turn allows small journals to easily provide article level metadata to the DOAJ, which is busy helping solve issues of discovera- 
bility and archiving. PKP software also enables projects like SciELO to offer journal hosting to broad constituencies of scholars, removing yet another barrier to participation. What can we learn from these basins of attraction? They are all international in scope and crossinstitutional in support structure. For the most part, they have focussed on the interaction of technical and social systems and addressed infrastructural issues. They are self-organizing and self-authorizing, often with humble beginnings and limited institutional support. They were created to fill a specific need for a particular set of communities. They empower smaller projects and scholars directly. Perhaps most interestingly, scholars who remain active in research frequently drive them. In short, OA works best when scholars take control of their own communications by coming up with their own solutions to validate and empower each other. The key questions moving forward are not, how can OA publications become sustainable? Most already are, though they could certainly use more university support. Rather, how can OA remove barriers of entry and exit to scholarly communications networks in order to provide equitable access? How can scholarly knowledge production remain self-authorizing without becoming marginalized? And what specific strategies to accomplish this do the above understandings suggest?

\section{Open Access in Practice}

Scholarly communications are, and have always been, complex and evolving social-technical systems. There is no moment when Open Access will be done because the material conditions of access are continually changing. Questions of openness and access have always been under negotiation. Open for whom? Accessible how? Anthropologists, for example, are quick to point out that the ethics of their research requires access restrictions (Kelty et al. 2008, 564). Legislating rigid definitions that favour particular worldviews can be divisive, but vigorous discussions over how best to achieve more open and equitable access are necessary to forging common ground.

\subsection{Reframe the Debate within Resilient Communications}

Both sustainability and publishing will continue to be prominent terms in the debate over OA. But instead of allowing the mention of sustainable publishing to slip into a discussion of business models predicated on protecting publishers, let's use it as an opportunity to segue into a discussion of what kind of scholarly communications system we want and how we can make it resilient in the face of technological, institutional and funding volatility. The sustainable publishing conversation precludes discussion of public and community provision of communications infrastructure, the resilient communications conversation leads to it. Framing the issue of access within resilient communications reminds us that we are continually creating and renewing what it means to engage in scholarship.

The Open Humanities Press (OHP) journal collective is an example of small-scale resiliency. Journals which are "part of OHP" were all founded, and continue to operate, independently. Some receive direct funding from national bodies, some indirect institutional support like teaching buyouts, some no institutional support whatsoever. Being part of the OHP journal collective simply means that the journal has been recognized by its peers for its internationally significant scholarly contribution in critical theory, is peer-reviewed, and that it is Open Access. It is easy to underestimate how important this moral support is. I have had more than one journal editor tell me that they were about to pack it in but that becoming part of OHP helped revitalize them. We launched the journals collective project in 2008 with 7 journals. There are now 17. The oldest OHP Journal has been publishing for 19 years, the median age is nine. If a journal should fold, the others are entirely unaffected. Managing the journals project costs nothing but people's time. As long as our editorial board members continue to volunteer their efforts, it will continue. But if for some reason OHP should fold, the journals are likewise unaffected. The OHP journals collective is a simple, easily implemented effort designed to help journals in the prestige economy while remaining materially resilient. 


\subsection{Support Practice-Based Initiatives - Small and Large}

Arguably, the most important thing about PLoS is not that it's an OA publisher. It is that PLoS is an on-going scholar-led experiment in reconfiguring scholarly communications to improve the practice of science itself. Practice-based initiatives demonstrate that the potential of Open Access is realized when it becomes integral to the practice of scholarship. As Gary Hall has pointed out "there is nothing intrinsically or inherently democratic or even political about open access" (Hall 2008, 197). Many of the battles in the OA movement can be traced, I think, to the mistaken assumption that there is some inherent politics of OA. Practice-based initiatives, be they configured as publishers, publications, tool developers, archives, or whatever, is where the OA movement explores the praxis, politics and ethics of Open Access. Recognizing that scholarly communications are not a monolithic system with a single solution, but a diverse set of practices of divergent communities is a natural outgrowth of this experience. We should advocate for and support mechanisms fully capable of embracing this diversity.

The Alliance for Networking Visual Culture's new authoring platform, Scalar (ANVC Scalar n.d.) is helping scholars collaboratively explore and think through the possibilities and implications of interactive "texts" enriched with machine-readable semantics and mixed media. The outgrowth of many years of experimentation with digital writing, Scalar has prioritised ease of use to eliminate the technical barriers preventing many scholars from participating in emerging forms of scholarly communication. In the same spirit that animates Open Access, ANVC has released Scalar as open source software.

Joanna Zylinska (2013) observes that as scholars participate in all aspects of the publication workflow, the labour relations in knowledge production become transparent. This experience is leading to new experiments in academic publishing that are more sensitive to the ethics of scholarly communications. The newly formed Mattering Press for instance, is making the idea of care integral to its operation while it explores "shifting the various, often asymmetrical, terms of engagement between publishers, authors, readers, and networks of distribution" (Mattering Press 2013).

The dynamics of scholarly communications are not just about changes in publication artefacts, but also about the shifts in relations between the actors. We cannot predict the future of scholarly communications but through praxis, scholars are in a much better position to see and analyse emerging opportunities and risks to scholarship.

\subsection{Use Metrics Tactically While Recognizing Their Risks}

Judgements of scholarly quality and significance are of two kinds: community judgements and instrumental judgements. The function of the first type is community recognition and support. Judgements of this type are always content based and given by the community actively engaged in the specific research area in question. That is to say, these are thoughtful, fully qualified judgements of experts in their fields. Traditional peer review, practised well, is of this type. Instrumental judgements, on the other hand, are made by non-experts and rely on indirect measures. Inclusion in ISI, bibliometrics and usage metrics fall into this category. Despite their many shortcomings, national funding bodies and universities have been enthusiastic in their adoption of instrumental judgements. To the extent that its rankings translate into administrative decisions around funding, work allocation, promotion and tenure, ISI remains one of the biggest obstacles to OA publishing by scholars. Article Level Metrics (ALMs) and other Internet usage derived measures of "impact" look to be the counterweight that OA publishers need to finally dislodge ISI. Apart from any potential value as measures, our experience at OHP has been that usage metrics can be very motivating and rewarding to authors and editors. Tactically, ALMs are smart move for OA, especially when they are promoted thoughtfully, as in the SF Declaration. Strategically, over the longer term, we need to remain mindful that usage-based metrics are a double-edged sword. There is no single time scale over which the "impact" of any book or article can be fully quantified. Indeed, for many fields the typical time scales at which metrics may be indicative of impact are longer than funding and assessment cycles, and will therefore be harmful in guiding those decisions. 
ALMs will therefore disadvantage fields like arts, humanities and mathematics as well as longer form publications like monographs.

But in addition to further entrenching existing disciplinary disadvantages, ALMs are opening the lid of a veritable Pandora's box of potential risks to the practice of scholarship as a self-authorizing discourse. Metrics have become central to the allocation of public monies to research. From the policy perspective, quantifying benefits of research spending is not a concern that can be simply dismissed; it is a problem that must be solved. Metrics are about establishing economies of prestige and oversight, but knowledge production is not a zero sum game. Management by metrics nevertheless turns it into one. From this perspective, the intensification of metrics in the allocation of resources represents an existential threat to scholarship as a self-authorising knowledge practice.

Usage data are the primary means to commodify information on the web. With the collection and exploitation of usage data a complex set of actors becomes involved in directing the results to particular outcomes. These are outcomes that are negotiated by proprietary systems and protected by trade secrets. Discovery and recommendation platforms like Google Scholar and Mendeley have business models that are driven by usage data. If scholars should embrace social web technologies in their communications practices, then might not the usage data itself be construed as part of the scholarly record? It seems to me there are very real concerns about the collection of usage data in relation to academic freedom. Though these threats may seem remote to many scholars, the increasing politicization of scholarship is worth pondering. Climate science is an obvious example, but all the academic fields have had nasty brushes with politically motivated attacks in recent years. The increasingly granular surveillance capabilities inherent in usage data collection will impact scholars as a group in their professional lives, much as it is impacting individuals in their (formally) private lives. How this might distort research needs to be monitored closely.

\subsection{Insist on Public and Community Provision of Critical Infrastructure}

Capital flows to wherever it gets the highest returns. It seems unlikely that systems of communication that prioritize open and equitable access will ever command margins as high as strategies involving barriers of some kind. Value-added services are obvious points of strategic positional control. In embracing value-added services as a panacea for the overplayed business model problem, institutions are rapidly moving to a system of scholarly communications where critical pieces of infrastructure are being moved from public institutions to less transparent and accountable private ones. Growth in publications revenue has become too modest to meet the expectation of continued sector leading financial performance. In response, incumbents are in the process of leveraging their publishing portfolios, strategic positions in the supply chain, and political power to muscle in on the much bigger research budget, rebuilding barriers of entry to competitors and locking in scholars and universities as they do.

Having outsourced many of their traditional jobs and with their primary mission of collections development made largely redundant by the shift to digital, libraries seem to be outsourcing parts of their archival mission just as many scholarly fields have or are entering a phase where the distinctions between instrumental data, research corpus, discovery tools, analytic methods, and presentation of findings are becoming increasingly blurred. Scholarly rigour demands reproducibility, but reproducibility demands not just that the content, models and data be openly accessible but also their instantiations in software. Direct archival control of content and data leads to control over applications, protocols, APIs, usage data, discovery paths, and ultimately, the very methodologies of research. Archives in particular are too important to allow self-interested corporations to define their structure, function, and terms of use. Even if access to content becomes more open, the kind of access needed to advance careers will depend on the service overlays, and the dream of equitable access will recede. Open Access projects focused on capacity building and infrastructure have arguably done the most to push OA forward. They deserve much more support than they have been getting. 
It is matter of some shame for the OA movement that promising infrastructural projects like DOAJ and PKP, to name just two, have received so little cross-institutional support.

\subsection{Redouble Grassroots Advocacy}

In the UK, the first encounter many scholars are having with the idea of OA is through administrative communications about the Finch report. Many scholars are suspicious of managerialist discourse as they've seen their job security, autonomy, and academic freedoms eroded under its banner. In retrospect, focussing on the policy level debate and prioritizing top-down solutions to OA like repository mandates has led to OA becoming identified as a managerialist program in many scholars' minds, leading to fundamental confusions over the purpose and goals of OA. The experience at OHP has been that, although scholars may have only a passing interest in OA, the more they publish OA the more they want to. Academics are attracted to OHP's journals, books and labs projects as interesting academic venues, not because they are OA. But upon taking control of their communications through direct participation, academics experience an empowerment that transforms them from being casual participants to active OA advocates. Organic growth, discipline by discipline, community by community along the lines of established disciplinary networks may be less visible, but it is more robust than trying to establish new networks under other banners. Ultimately the only real power base of the Open Access movement is scholars. The OA movement would do well to put more effort into grassroots advocacy.

Two of the five largest commercial publishers, and the largest not-for-profits (Oxford University Press, Cambridge University Press) are domiciled in the UK. Academic publishing is a significant industry for the UK in terms of both money and soft power, so it is not surprising that fundamental tensions surrounding OA should surface in the UK more clearly than elsewhere. What the Finch report and the UK policy response tell us is that the Open Access movement has come to its Lessig moment. The argument for Open Access has been made convincingly - within the very terms of the dominant frame of the policy debate - yet we find the policy response is crafted to protect incumbents first and foremost, even at the expense of public interests.

$\mathrm{OA}$ is strong and vibrant but we are rightly impatient. Significant challenges remain. We need libraries to demonstrate collective resolve vis-à-vis infrastructure. We need universities to recognize editorial service as relevant. We need funders to acknowledge the risks and limitations of metrics. But most of all, we need to communicate better with our colleagues, informing them of the stakes and involving them in the practice of Open Access. This is the only way to develop the strong grassroots support that puts scholars at the centre of their communications, where they belong.

\section{References}

ANVC Scalar. n.d. "The Alliance for Networking Visual Culture » Overview." http://scalar.usc.edu/scalar/

ARL. 2011. ARL Statistics 2010-2011. Washington, DC: Association of Research Libraries.

Biagioli, Mario. 2002. From Book Censorship to Academic Peer Review. Emergences: Journal for the Study of Media \& Composite Cultures 12 (1): 11-45. doi:10.1080/1045722022000003435.

Elsevier. 2005. A Short History of Elsevier. Elsevier.

Fuchs, Christian and Marisol Sandoval. 2013. The Diamond Model of Open Access Publishing: Why Policy Makers, Scholars, Universities, Libraries, Labour Unions and the Publishing World Need to Take Non-Commercial, Non-Profit Open Access Serious. tripleC: Communication, Capitalism \& Critique 11 (2): 428-443.

Hall, Gary. 2008. Digitize This Book! The Politics of New Media, or Why We Need Open Access Now. Electronic Mediations 24. Minneapolis, London: University of Minnesota Press.

Kelty, Christopher M., Michael M.J. Fischer, Alex Golub, Jason Baird Jackson, Kimberly Christen, Michael F. Brown and Tom Boellstorff. 2008. Anthropology of/in Circulation: The Future of Open Access and Scholarly Societies. Cultural Anthropology 23 (3): 559-588.

Lessig, Lawrence. 2007. Required Reading: The Next 10 Years | Lessig. Blog. Lessig. June 19. http://www.lessig.org/2007/06/required-reading-the-next-10-y-1/ 
Mattering Press. 2013. Mattering Press - Home. Project. http://www.matteringpress.org/.

Odlyzko, Andrew. 2013. Open Access, Library and Publisher Competition, and the Evolution of General Commerce. arXiv:1302.1105 [physics] (February 5). http://arxiv.org/abs/1302.1105.

PLoS. 2012. Financials | PLOS. http://www.plos.org/about/what-is-plos/financials/.

Spier, Ray. 2002. The History of the Peer-Review Process. TRENDS in Biotechnology 20 (8): 357358.

Strieb, Karla L. and Julia C. Blixrud. 2013. The State of Large-Publisher Bundles in 2012. Research Library Issues: A Report from ARL, CNI, and SPARC (282): 13-20.

UC Berkeley Library. 2012. Hot Topics: Publisher Mergers - Scholarly Communication - Library Collections - UC Berkeley. February 16. http://www.lib.berkeley.edu/scholarlycommunication/publisher_mergers.html.

Willinsky, John, and Ranjini Mendis. 2007. Open Access on a Zero Budget: A Case Study of Postcolonial Text. Information Research 12 (3). http://informationr.net/ir/12-3/paper308.

Young, Philip. 2009. The Serials Crisis and Open Access: A White Paper for the Virginia Tech Commission on Research. White Paper. Virginia: University Libraries Virginia Tech.

Zylinska, Joanna. 2013. Joanna Zylinska - Aftermedia - Technology Vs Tradition: The Open Access Debate. Blog. Aftermedia. November 15.

http://joannazylinska.squarespace.com/aftermedia/2013/11/15/technology-vs-tradition-the-openaccess-debate.html

\section{About the Author}

David Ottina

is Co-Founder and Co-Director of Open Humanities Press. 